\title{
Isolation and Characterization of Phosphate Solubilizing Actinomycetes from Rhizosphere Soil
}

\section{Faried, Al-Shaimaa M.; H.M. Mohamed; M.M. El-Dsouky and Hamdia M. El-Rewainy}

Department of Soils \& Water, Faculty of Agriculture, Assiut University, Assiut, Egypt.

\section{Abstract}

Eighteen actinomycetes strains were isolated from rhizosphere soils taken from experimental farm of faculty of agriculture, Assiut University, Egypt, planted with wheat, faba bean and clover. Out of the 18 isolates, $9(50 \%)$ showed an ability to solubilize inorganic phosphates, based on inducing clear zones around their colonies growing on a tricalcium phosphate medium after incubation for 10 days at $28{ }^{\circ} \mathrm{C}$. The phosphate solubilization index of strains A1, A2, A3, A4, A5, A7, A8, A10 and A18 on pikovskaya's modified agar medium were 3.40, 2.40, $2.57,4.50,3.10,1.57,2.10,3.83$ and 1.83 , respectively. The highest phosphate solubilization index was recorded by the strain A4 and the lowest by the strain A7. The isolates were further studied for ability to solubilize phosphorus from insoluble phosphate in Pikovskaya's liquid medium containing tricalcium phosphate. Amounts of phosphorus solubilized by the actinomycete strains A1, A2, A3, A4, A5, A7, A8, A10 and A18 were 52, 45, 46, 78, 32, 37, 36, 55 and 45 $\mathrm{mg} / 100 \mathrm{ml}$ culture, respectively. The highest amount of $\mathrm{P}$ solubilized $(78 \mathrm{mg} / 100$ $\mathrm{ml}$ culture) was recorded for the actinomycetes strain A4, which showed the highest of phosphate solubilization index (4.5) and the lowest $\mathrm{pH}$ (4.00) in a 10day liquid culture medium. The solubilized amounts of $\mathrm{P}$ and the determined phosphate solubilization index for the actinomycete isolates are compatible with the acidity ( $\mathrm{pH}$ values) produced in their cultures. This indicates that the organic acids produced from fermentation of sugars in the media by actinomycete isolates are the main cause of solubilization. Nine phosphate solubilizing actinomycete isolates were identified on the basis of colony characteristics, microscopic observation and biochemical test. All nine isolates of actinomycetes were observed to be from the genus Streptomyces.

Keywords: Isolation; Streptomyces; inorganic phosphate; phosphate solubilization; Identification.

\section{Introduction}

Phosphorus (P) is an essential macroelement for plants, yet the total concentration of $\mathrm{P}$ in soils ranges from $0.02 \%$ to $0.5 \%$; an average approximately $0.05 \%$. The variation being largely due to differences in the weathering intensity and parent material composition (Stevenson, 1986). Thus, to increase the availability of phosphorus for plants, large amount of fertilizers are used on a regular basis, yet after application, a large proportion of the fertilizer phosphorus is quickly transferred to an insoluble form (Omer, 1998). In calcareous soils, phosphorus fertilizers are fixed by calcium carbonate through adsorption and precipitation, resulting in an efficiency of less than $20 \%$ (Tisdale 
et al. 1993). The solubilization of phosphate-bearing inorganic materials by microorganisms would seem to be an attractive solution that has been actively studied during the last decade. Several mechanisms, such as lowering the $\mathrm{pH}$ by acid production, ion chelation and exchange reaction in the growth environment, have been reported to play a role in $\mathrm{P}$ solubilization by phosphatesolubilizing microorganisms (PSM) (Halder et al., 1991; Rajankar et al., 2007).

Among these PSM, Actinomycetes are of special interest since these filamentous sporulating bacteria are able to develop in extremely different soils (Jiang et al., 2005; Pathom-Aree et al., 2006) and produce various substances (anti-fungi, insecticides, anthelminthics, phytohormone-like compounds etc.) that could benefit plant growth (Fabre et al., 1988; Manulis et al., 1994; Ikeda, 2003; Jain and Jain, 2007).

Hamdali et al. (2008) showed that the abundance of actinomycetes solublizing Moroccan rock phosphate, from a Togolese phosphate mine, was approximately $19 \%$. Reports in the literature suggested that microbial solubilization of mineral phosphate might be either due to the excretion of organic acids causing acidification of the external medium (Whitelaw, 2000), or to the excretion of chelating substances (such as sidero-phores) that form stable complexes with phosphorus adsorbents (aluminium, iron and calcium) (Welch et al.,2002), and thus increase phosphate solubilization. The aim of this study was: isolation, characterization and identification of actinomy- cetes from plant rhizosphere soil and test their ability to solubilizing inorganic phosphate.

\section{Materials and Methods \\ Enrichment and Isolation of actin- omycetes strains:}

Soil samples were collected from rhizosphere region of three different plants (wheat, faba bean and clover), growing at the Experimental Farm of Faculty of Agriculture, Assiut university, Egypt. Soil suspensions were made, where $1 \mathrm{~g}$ of the soil sample was taken and mixed with $100 \mathrm{ml}$ of sterile distilled water. The soil suspension was shaken vigorously under room temperature $(28 \pm 2$ ${ }^{\circ} \mathrm{C}$ ) on an orbital shaker at $200 \mathrm{rpm}$ for $1 \mathrm{~h}$. Isolation of actinomycetes was performed by the plating technique using Starch Casein agar (SCA) medium of the following composition: starch $5 \mathrm{~g}$, casein $5 \mathrm{~g}, \mathrm{NH}_{4} \mathrm{So}_{4}$ $0.5 \mathrm{~g}$, agar $20 \mathrm{~g} / \mathrm{L}$ (Kuster and Williams.,1964). The medium was prepared and sterilized at $121{ }^{\circ} \mathrm{C}$ in 15 Ibs pressure for 15 minutes. Before pouring in sterile plates, the cooled medium was supplemented with Streptomycin $(30 \mu \mathrm{g})$ and griseoflavin $(50 \mu \mathrm{g})$ to prevent the bacterial and fungal growth. The medium was poured into sterile petri plates. Aloquotes of $0.1 \mathrm{ml}$ of the diluted soil samples were surface spread on the poured plates and incubated at $28 \pm 2$ ${ }^{\circ} \mathrm{C}$ for 7-10 days. After incubation, the actinomycetes colonies, developing on the medium, characterized as dry white to grey powdery, were separately isolated from the agar surface for purification and further studies. 
Purification of actinomycetes:

The isolated pinpoint colonies were purified by streaking and repeated sub culturing on plates of starch casein agar medium and incubated at $28 \pm 2{ }^{\circ} \mathrm{C}$ for $7-10$ days. Plates were checked for the growth of typical actinomycetes colonies up to 10 days. The purified actinomycete isolates were kept on SCA slants for characterization by morphological, biochemical and physiological tests. The purified cultures were then grown on SCA medium and preserved at $4{ }^{\circ} \mathrm{C}$ temperature for further macroscopic and microscopic characterization.

\section{Screening of phosphate solubilizing actinomycetes:}

The isolated actinomycetes cultures were inoculated on "Pikovskaya's" agar medium, modified by (Sundara and Sinha, 1963), containing tricalcium phosphate, as a sole phosphorous source, for selective screening the actinomycetes that have the ability to release inorganic phosphate from tricalcium phosphate. The medium used have the following composition: Glucose, $10 \mathrm{~g}$; $\mathrm{Ca}_{3}\left(\mathrm{PO}_{4}\right)_{2}, 5 \mathrm{~g} ;\left(\mathrm{NH}_{4}\right)_{2} \mathrm{SO}_{4}, 0.5 \mathrm{~g} ; \mathrm{KCl}$, $0.2 \mathrm{~g} ; \mathrm{MgSO}_{4} .7 \mathrm{H}_{2} \mathrm{O}, 0.1 \mathrm{~g} ; \mathrm{MnSO}_{4}$ trace; $\mathrm{FeSO}_{4}$ trace $(\mathrm{pH} 7)$. The inoculated plates were incubated at $30^{\circ} \mathrm{C}$ for 7-10 days. After the completion of the incubation period, the plates were examined for the presence of clear zone (Halo Zone) around the colonies, which indicates the extent of phosphate solubilization and the ability of solubilizing inorganic phosphate.

\section{Determination of solubilizing index (SI):}

A spot of the culture suspension of each isolate was inoculated on modified Pikovskaya's agar plates and incubated for 10 days at $28{ }^{\circ} \mathrm{C}$, then the diameter of the clear zone around the growing colony was measured, successively after 10 days. The phosphate solubilization index (SI) is the ratio of total diameter (colony + halo zone) and the colony diameter $(\mathrm{mm})$ was determined, according to Edi- Premono et al. (1996). SI were measured after 2 to 7 days incubation and all the observations were recorded in triplicate.

Quantitative determination of phosphate solubilization by actinomycetes:

The ability of the actinomycete isolates to solubilize insoluble tricalcium phosphate was measured in 100 $\mathrm{ml}$ aliquots of Pikovskaya's liquid medium. Actinomycetes strains were grown each on $100 \mathrm{ml}$ aliquot of of Pikovskaya's liquid medium in 200 $\mathrm{ml}$ Erlenmeyer flask. The flasks were incubated for 10 days at $28^{\circ} \mathrm{C}$, then the cultures were filtrated and centrifuged at 10000 r.p.m. for 10 minutes. Soluble phosphorus in the supernatant and blank sample of the medium were determined by the chlorostannous phosphor-molybdic acid method (Jackson, 1973).

\section{Results and discussion}

Actinomycetes are widely distributed in many natural habitats including various soil, freshwater habitat, marine habitat, organic matter and colonizing plants (Chandramohan, 1991). A total of 62 isolates of actinomycetes were isolated from 7 soil samples collected from Agriculture Research Center Semongok, Sarawak (Jeffrey, 2008). Lo et al. (2002) no- 
ticed that there are about 100 genera of actinomycetes in the soil.

Actinomycetes are saprophytic soil inhabitants, and are sources of biologically active compounds such as antifungal, antibacterial compounds or plant growth promoting substances used in agriculture. Soil under medicinal plants is considered as an enrichment environment because of addition of root secretions and litter of plants in rhizosphere soil that serve as nutritive source for biological activity of microorganisms.

Isolation of Actinomycetes from soil sample

In the present study, totally 18 actinomycetes colonies with different morphotypes were isolated by direct plating of the soil of experimental farm of Faculty of Agriculture, Assiut University, Egypt, planted with wheat, faba bean and clover. The obtained isolates were labeled A1, A2, $\mathrm{A} 3 \ldots$ and $\mathrm{A} 18$ based on their differences in colony morphology. The actinomycete isolates exhibited good growth in starch-casein agar medium. The Majority of the isolates grew within 7-10 days and sporulation was noticed after 12-14 days. The strains were purified by visual, microscopic and cultivation methods, and were maintained at $4{ }^{\circ} \mathrm{C}$ on the same medium which was used for isolation.

\section{Screening of isolated actinomycetes for Phosphate Solubilization}

The purified actinomycete isolates were screened for the solubilization of inorganic phosphates on Pikovskaya's agar medium. Out of the 18 isolates, 9 (50\%) showed an ability to solubilize inorganic phosphates based on inducing clear zones around their colonies (Figure 1). The phosphate solubilization index, $\mathrm{pH}$ values and amounts of phosphorus solubilized from tricalcium phosphate (TCP) by the nine actinomycetes isolates are shown in Table 1. The phosphate solubilization indexes of the strains A1, A2, A3, A4, A5, A7, A8, $\mathrm{A} 10$ and A18 were $3.40,2.40,2.57$, $4.50,3.10,1.57,2.10,3.83$ and 1.83 , respectively. The highest phosphate solubilization index was recorded by the strain A4 and the lowest by the strain A7. 


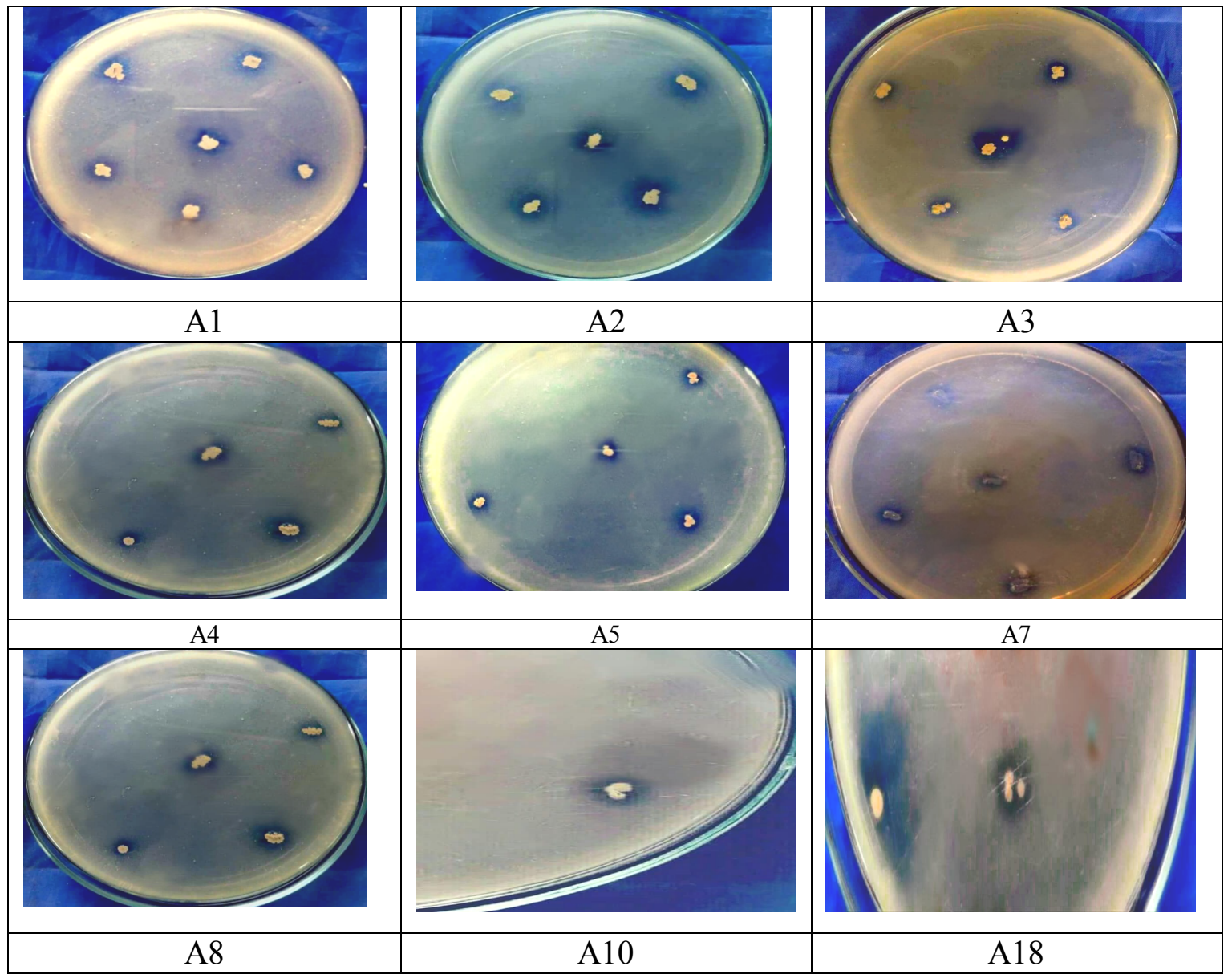

Figure 1. Colonies of isolated actinomycete strains grown for 10- days on Pikovskaya's medium showing the clear zone of phosphate dissolution.

The isolates were further studied for ability to solubilize phosphorus from insoluble phosphate in Pikovskaya's liquid medium containing tricalcium phosphate. Amounts of phosphorus solubilized from tricalcium phosphate by the isolated actinomycetes strains are shown in Table (1) and figure (2). Amounts of phosphorus solubilized by the actinomycete strains A1, A2, A3, A4, A5, A7, A8, A10 and A18 respectively were: $52,45,46,78,32,37,36,55$ and 45 $\mathrm{mg} / 100 \mathrm{ml}$ culture, respectively. The highest amount of $\mathrm{P}$ solubilized (78 $\mathrm{mg} / 100 \mathrm{ml}$ culture) was recorded for actinomycetes strain A4, which also showed the highest phosphate solubilization index (4.5) and the lowest $\mathrm{pH}$
(4.00) in a 10-day old culture. The results also showed that the lowest amount of $\mathrm{P}$ solubilized was recorded by the actinomycete strain A5 (32 $\mathrm{mg} / 100 \mathrm{ml}$ culture). The solubilized amounts of $\mathrm{P}$ and the determined phosphate solubilization index of the actinomycete isolates are, in general, compatible with the acidity ( $\mathrm{pH}$ values) produced in their cultures (Table 1 and Figure 2). This indicates that the organic acids produced from fermentation of sugars in the medium by the actinomycete isolates may be the main cause of solubilization. These results are in agreement with the observation of Hamdali et al. (2008) who reported high amount of phosphate solubilizing activity by Strep- 
tomyces griseus and Streptomyces cavourensis (58.9 and $83.3 \mathrm{mg} / 100$ $\mathrm{ml}$ respectively), and also the repoted amount of phosphate solubilized by Micromonospora auranticawas (39 $\mathrm{mg} / 100 \mathrm{ml}$ ). Thus, it is suggested that these phosphate solubilizing actinomycetes may be used as plant growth promoters, since phosphate solubilization increases the soluble phosphate concentration, which is essential for plant growth (Balakrishna et al., 2012).

Reports in the literature suggested that microbial solubilization of mineral phosphate might be either due to the excretion of organic acids causing acidification of the external medium (Whitelaw, 2000), or to the excretion of chelating substances (such as sidero-phores) that form stable complexes with phosphorus adsorbents (aluminium, iron and calcium) (Welch et al. 2002; Hamdali et al. 2008) and thus release the attached phosphate in soluble form
Hamdali et al. (2012) isolated five strains of actinobacteria from Togolese phosphate mine at Morocco, which showed the most active growth and $\mathrm{P}$ solubilization capability. These isolates were shown to be able to solubilize rock phosphate in liquid cultures. The study of mechanisms involved in these weathering processes indicated that the isolates produce siderophores but not organic acids. Actinomycete are rarely reported for their role in organic acid production despite the fact that they are the major sources of many microbial bioactive metabolites (Rozycki and Strzelczyk 1986; Jog et al., 2014). The major organic acids reportedly produced by actinobacteria are citric acid, gluconic acid, lactic acid, malic acid, and oxalic acid (Chen et al., 2006; Yi et al., 2008; Jog et al., 2014).

Table 1. Determination of solubilizing index (SI), amounts of phosphorus solubilized by the actinomycete strains* and $\mathrm{pH}$ values.

\begin{tabular}{|l|c|c|c|}
\hline Strains NO: & $\begin{array}{c}\text { Solubilizing Index } \\
\text { (SI) }\end{array}$ & $\begin{array}{c}\text { Solubilized phosphorus } \\
\text { mg / 100 ml culture }\end{array}$ & pH values \\
\hline A1 & 3.40 & 52 & 4.20 \\
\hline A2 & 2.40 & 45 & 4.37 \\
\hline A3 & 2.57 & 46 & 4.43 \\
\hline A4 & 4.50 & 78 & 4.00 \\
\hline A5 & 3.10 & 32 & 4.12 \\
\hline A7 & 1.57 & 37 & 4.32 \\
\hline A8 & 2.10 & 36 & 3.33 \\
\hline A10 & 3.83 & 55 & 4.18 \\
\hline A18 & 1.83 & 45 & 4.55 \\
\hline
\end{tabular}

*Amounts of solubilized $\mathrm{p}$ by actinomycetes isolates grown on Pikovskaya's medium for 10 days.

** $\mathrm{pH}$ values of cultures after 10 days growth. 


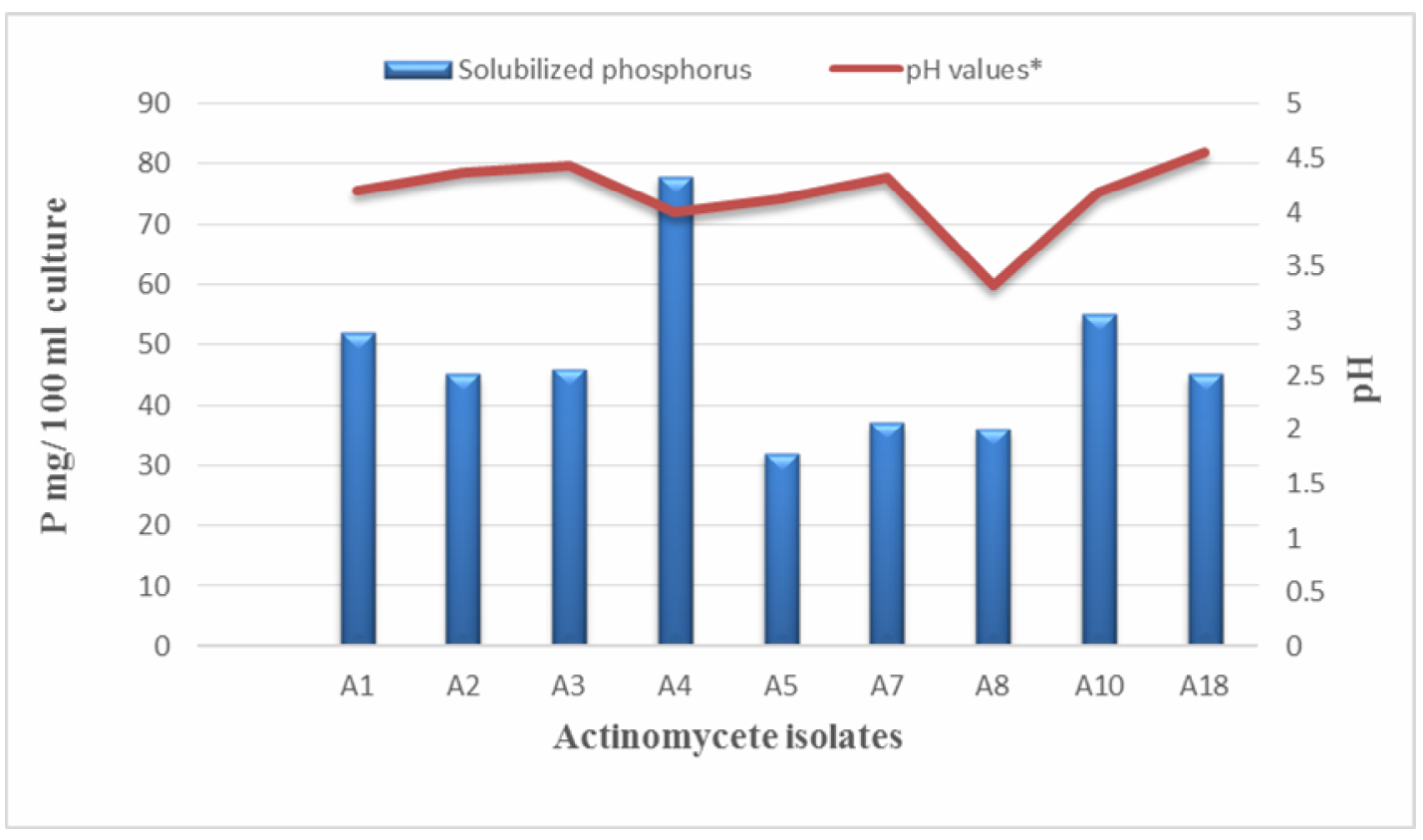

Figure 2. $\mathrm{pH}$ values and amounts of phosphorus solubilized by the isolated actinomycete strains grown on modified Pikovskaya's medium for 10 days.

Characteristics of the phosphate solubilizing actinomycete isolates:

Results of the tested morphological, cultural and physiological characteristics of the nine phosphate solubilizing actinomycete isolates are shown in Table (2). The colony size of nine actinomycete isolates was in the range between 4.6 to $10.3 \mathrm{~mm}$. The highest colony size was found in strain A5 (10.3 mm) and the lowest colony size was found in strain A3 (4.6 mm). The colony surface was cottony in all nine isolates. The colony edge was filamentous in strains A1, A2, A3, A4, A5, A10 and A18, but was the rizoid in strain $\mathrm{A} 7$ and lobate in strain A8. All actinomycete isolates were showed pellicle forma- tion on the surface of starch casein broth culture. Each of the isolates were later categorized according to their pigmentation or colony colour ranging from whitish, yellowish white and grey.

In the characterization of these isolates several biochemical tests were performed and results were presented in Table (2). All strains were able to use glucose fructose, sucrose, lactose, mannitol as sole carbon sources. All actinomycete isolates were able to hydrolysis starch, casein and urea. The results of microscopic features showed that, nine isolates have Spiral chains of spores with different morphology (figure 3 and figure 4). 


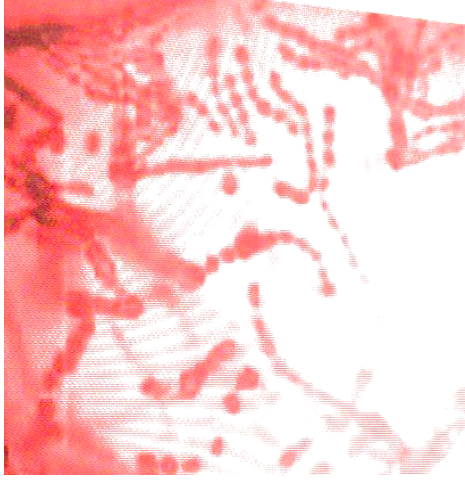

A1

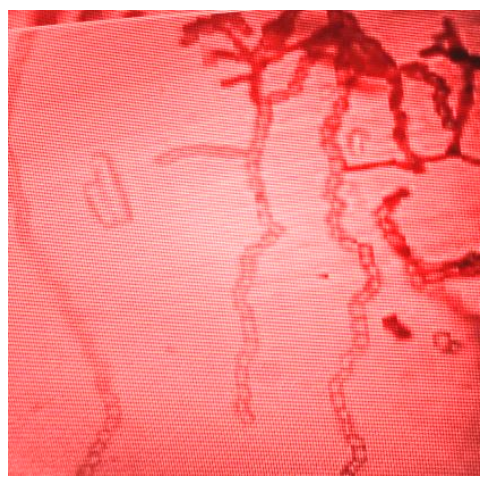

A4

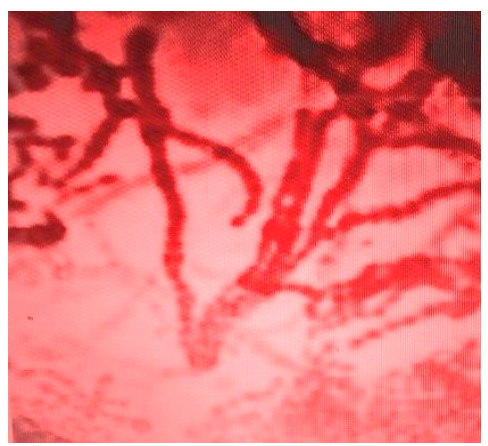

A8

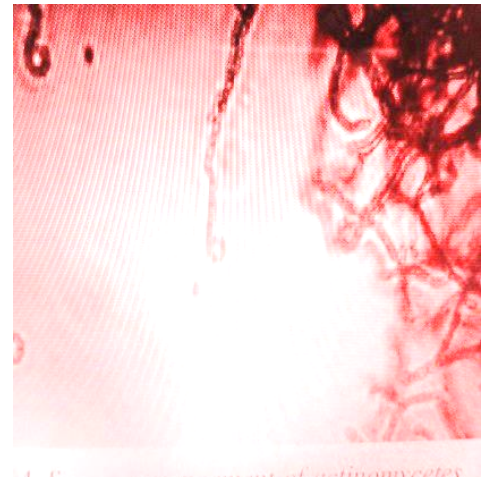

A2

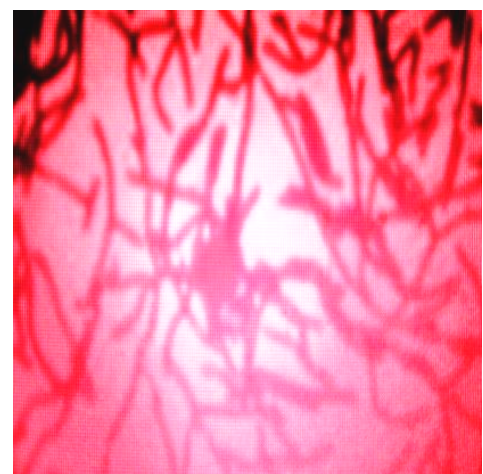

A5

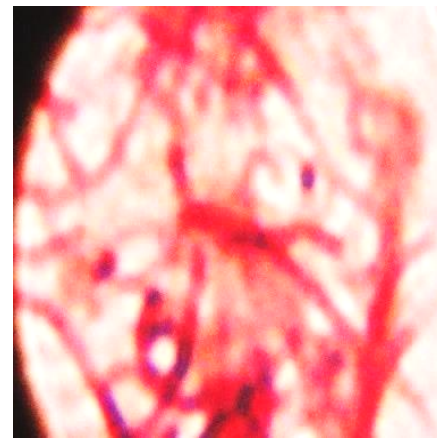

A10

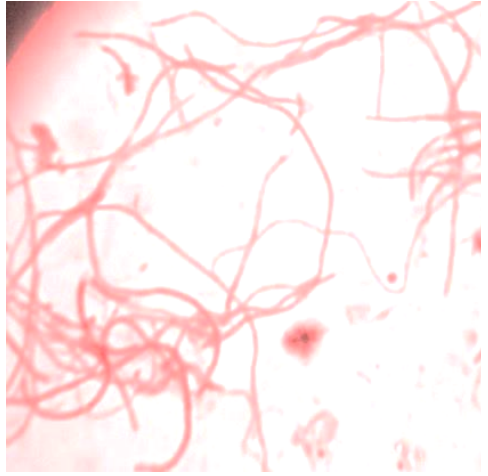

A3

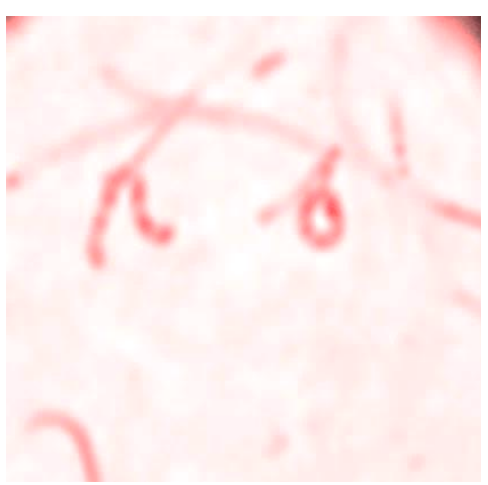

A7

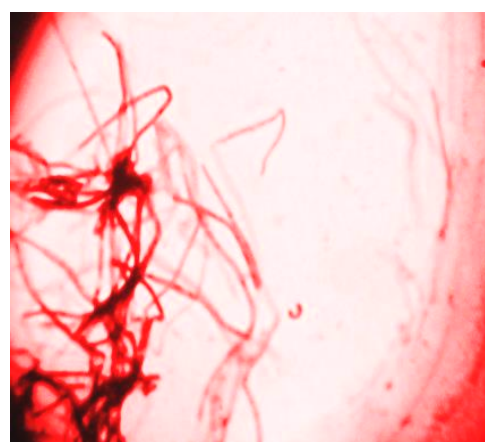

A18

Figure 3. Mycelia of the actinomycete isolates from $72 \mathrm{hrs}$ old cultures on starch casein agar medium. (Cover slip technique, $4000 \mathrm{x}$ magnification) 


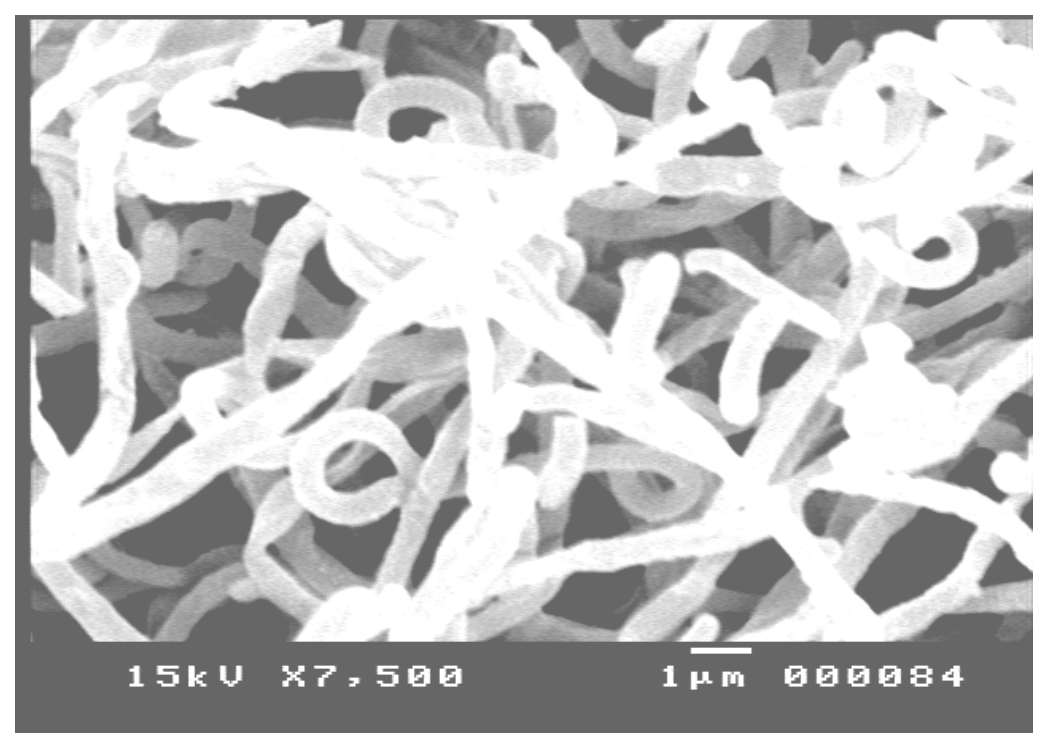

Actinomycetes strain A4

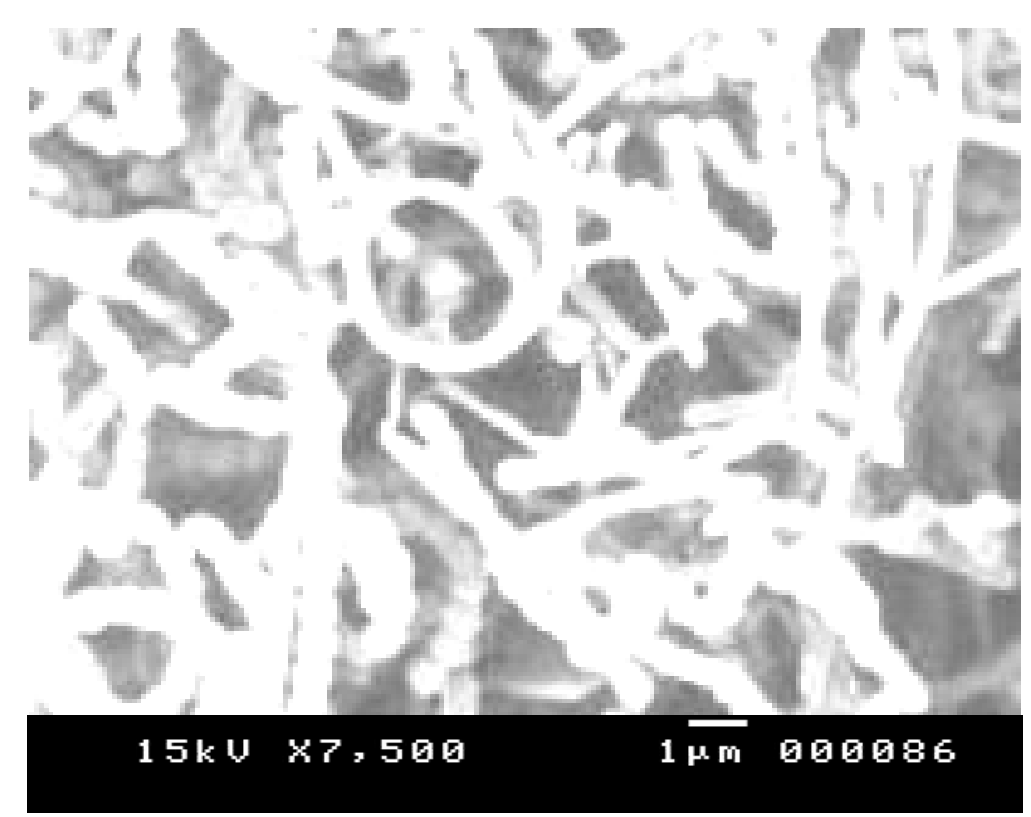

Actinomycetes strain A10

Figure 4. A scanning electron microscope picture for actinomycete isolates (A4 and A10) from $72 \mathrm{hrs}$ old cultures on starch casein agar medium. (10000 x magnification)

Identification of phosphate solubilizing actinomycete isolates:

The nine phosphate solubilizing actinomycete isolates were identified on the basis of colony characteristics, microscopic observation and biochemical tests. Spore chain arrangements observed using research microscope and scanning electron micro- scope showed that of all the isolates bear spore spiral chains. The colony surface was cottony and colony colour ranging from whitish, yellowish white and grey. All actinomycete isolates were able to hydrolysis starch, casein, urea and use glucose fructose, sucrose, lactose, mannitol as sole carbon sources. In accordance with the 
aerial mycelium, spiral spore chain and colony color established in Bergey's Manual of Determinative Bacteriology, $9^{\text {th }}$ edition (Daltimor 1994), the nine isolates could be grouped under the genus Streptomyces.

Although result obtained for colony colour showed that the actinomycetes isolated could be grouped into three colours (whitish, yellowish white and gry). According to study done by Lo et al. (2002) actinomycetes may belong to the same genus although their colours might be different because they give a broad colour group diversity. According to (Shirling and Gottlieb 1966), the species belonging to the genus Streptomyces may be divided into three sections, particularly rectiflexibile, retinaculiaperti and Spirales.

\section{References}

Balakrishna, G., Shiva S. A. and Pindi, P.K. (2012). Isolation of Phosphate Solibulizing Actinomycetes from Forest Soils of Mahabubnagar District, IOSR Journal of Pharmacy, 2(2): 271-275.

Chandramohan, D. (1991). Coastal microbial processe In: Natarajan. R, Dwivedi SN, Ramachandran $\mathrm{S}$ (eds). Coastal zone management (In Tamilnadu state, India). Ocean data centre, Anna University, Madras, $\mathrm{p} 93$.

Chen, Y.P., Rekha P.D., Arun, A.B., Shen, F.T., Lai. W.A. and Young, C.C. (2006). Phosphate solubilizing bacteria from sub-tropical soil and their tricalcium phosphate solubilizing abilities. Appl Soil Ecol, 34:33-41.

Daltimor, M.d. (1994). Bergey's Manual of Determinative Bacteriology, $9^{\text {th }}$ ed, Williams and wilkins company.

Edi Premono, M., Moawad, A.M. and Velk, P.L. (1996). Effect of phos- phate-solubilizing Pseudomonas putida on the growth of maize and its survival in the rhizosphere. Indones. J. Crop Sci,. 11:13-23.

Fabre, B., Armau, E., Etienne, G., Legendre, F. and Tiraby, G. (1988). A simple screening method for insecticidal substances from Actinomycetes. J. Antibiot. (Tokyo) 41, 212-219.

Halder, A.K., Mishra, A.K. and Chakarbarthy, P.K. (1991). Solubilization of inorganic phosphate by Bradyrhzobium. Ind J. Exp. Biol., 29: 28-31.

Hamdali, H., Bouizgarne, B., Hafidi, M., Lebrihi, A., Virolle, M.J, Ouhdouch, Y. (2008). Screening for rock phosphate solubilizing Actinomycetes from Moroccan phosphate mines. Appl.Soil Ecol., 38: 12-19.

Hamdali, H., Moursalou, K., Tchangbedji, G., Ouhdouch, Y. and Hafidi, M. (2012). Isolation and characterization of rock phosphate solubilizing actinobacteria from a Togolese phosphate mine, African Journal of Biotechnology, 11(2):

Ikeda,3 ID-3(20003). Pharmacological effects of ivermectin, an antiparasitic agent for intestinal strongyloidiasis: its mode of action and clinical efficacy. Nippon Yakurigaku Zasshi, 122: 527-538.

Jackson, M. L. (1973). Soil Chemical Analysis. Prentice - Hall, India.

Jain, P.K. and Jain, P.C. (2007). Isolation, characterization and antifungal activity of Streptomyces sampsonii GS 1322. Indian J. Exp. Biol., 45: 203-206.

Jeffrey, L. S. H. (2008). Isolation, characterization and identification of actinomycetes from agriculture soils at Semongok, Sarawak, African Journal of Biotechnology, 7 (20): 3697-3702. 
Jiang, Y., Li, W.J., Xu, P., Tang, S.K. and $\mathrm{Xu}, \mathrm{L} . \mathrm{H}$. (2005). Study on diversity of Actinomycetes from salt and alkaline environments.Wei Sheng Wu Xue Bae, 46: 191-195.

Jog, R., Pandhya, M., Nareshkumar, G.and Rajkumar, S. (2014). Mechanism of phosphate solubilization and antifungal activity of Streptomyces spp. isolated from wheat roots and rhizosphere and their application in improv-ing plant growth. Microbiology 160:778788.

Kuster, E. and Williams, S.T. (1964). Selective media for the isolation of Streptomycetes. Nature, 202: 928929.

Lo, C.W., Lai, N.S., Cheah, H.Y., Wong, N.K. and Ho, C.C. (2002). Actinomycetes isolated from soil samples from the Crocker Range Sabah. ASEAN Rev. Biodiversity and Environmental Conservation. July-Sept, 2002.

Manulis, S., Shafrir, H., Epstein, E., Lichter, A. and Barash, I. (1994). Biosynthesis of indole-3-acetic acid via the indole-3-acetamide pathway in Streptomyces spp. Microbiology, 140:1045-1050.

Omer, S.A. (1998). The role of rockphosphate-solubilizing fungi and vesicular-arbuscular-mycorrhiza (VAM) in growth of wheat plants fertilized with rock phosphate. World J. Microbiol. Biotech., 14: 211-218.

Pathom-Aree, W., Stach, J.E., Ward, A.C., Horikoshi, K., Bull، A.T. and Goodfellow, M. (2006). Diversity of Actinomycetes isolated from Challenger Deep sediment $(10,898 \mathrm{~m})$ from the Mariana Trench. Extremophiles 10: 181189.
Rajankar, P.N., Tambekar, D.H. and Wate, S.R. (2007). Study of phosphate solubilization efficiencies of fungi and bacteria isolated from saline belt of Purna river basin. Res. J. Agric. Sci., 3: 701-703.

Różycki H and Strzelczyk E (1986). Free amino acids production by actinomycetes isolated from soil, rhizosphere and mycorrhizosphere of pine (Pinus sylvestris L.) Zbl. Mikrobiol. (in print).

Shirling, E.B.and Gottlieb, D. (1966). Methods for characterization of Streptomyces species. Int. J. Syst. Bacteriol. 16: 313-340.

Stevenson, F.J. (1986). Cycle of Soil Carbon, Nitrogen, Phosphorus, Sulfur, Micronutrients. Wiley, New York.

Sundara Rao, W.V. and Sinha, M.K. (1963). Phosphate dissolving organisms in the soil and rhizosphere. Ind. J. Agric. Sci., 33: 272278.

Tisdale, S.L., Nelson, W.L., Beaton, J.D. and Havlin, J.L. (1993). Soil Fertility and Fertilizers, $5^{\text {th }}$ Ed. McMillan Publishing Co., New York.

Welch, S.A., Taunton, A.E., Banfield, J.F. (2002) Effect of microorganisms and microbial metabolites on apatite dissolution. Geomicrobiol J, 19:343-367.

Whitelaw MA (2000). Growth promotion of plants inoculated with phosphate solubilizing fungi.Adv. Agron. 69: 99-144.

Yi Y., Huang, W. and Ge. Y. (2008). Exopolysaccharide: a novel important factor in the microbial dissolution of tricalcium phosphate. World J Microbiol Biotechnol 24:1059-1065. 
عزل و توصيف الأكتينوميسيتات المذيبة للفوسفات من ريزوسفير التربة

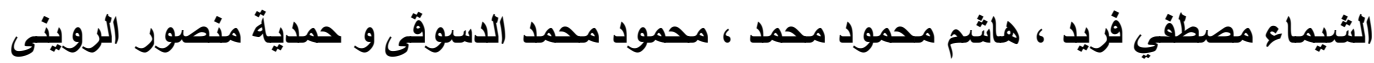

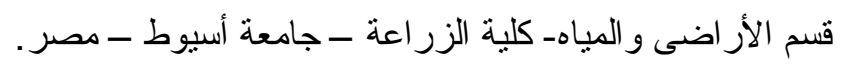

الملخص

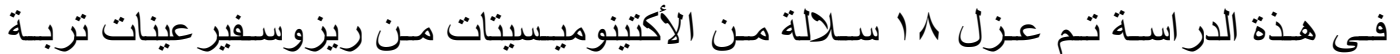

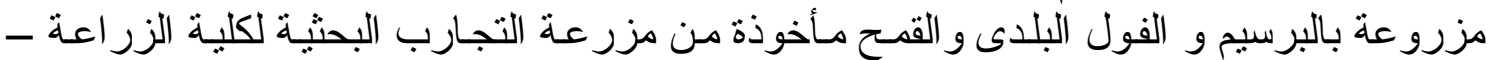

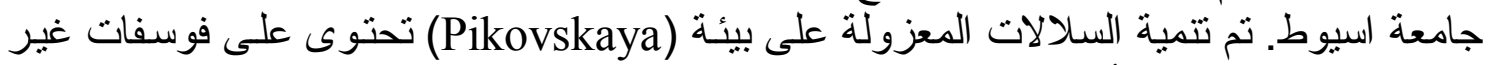

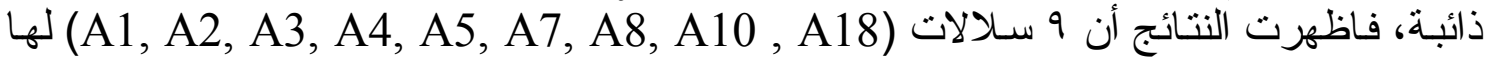
القدرة على اذابة الفوسفات فى البيئة وذلك من خلال تكوين هاله شفافة حول مستعمر ات السلالات المذيبة للفوسفات. وقد تم تقدير دليل الاذابة solubilizing index (ناتج قسمة قطر الهابة الهالـه الشفافة

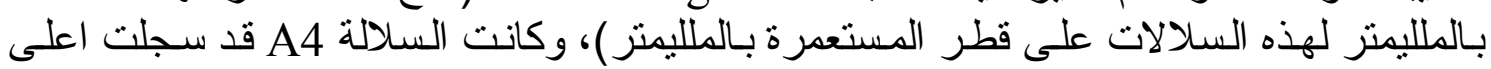

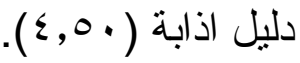
وفى تجربة اخرى تم تقدير قدرة السلالة على اذابـة الفوسفات الغير ذائبـة كميا وذلك بتتميـة

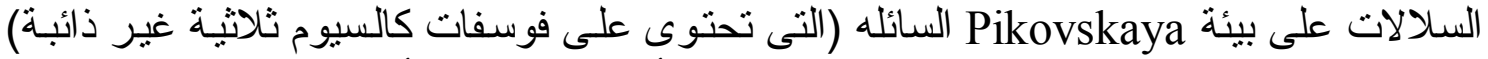

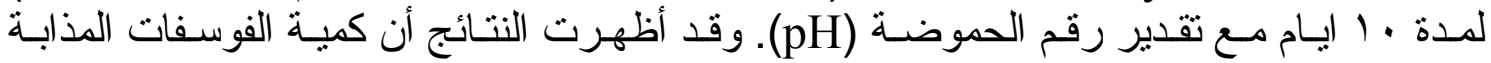

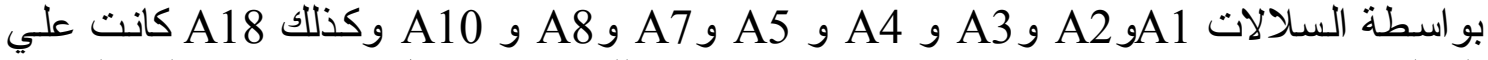

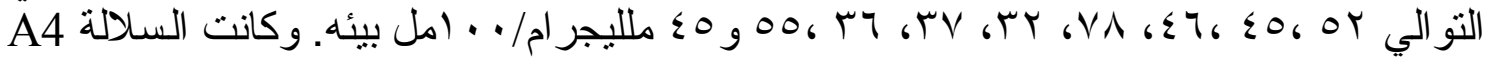

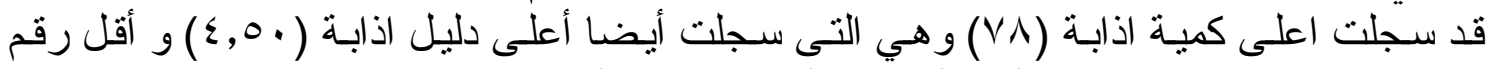

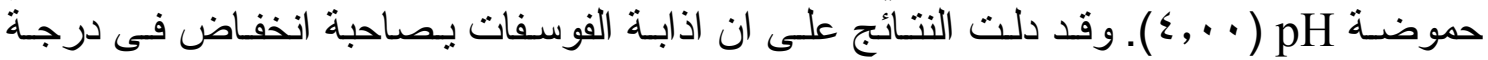

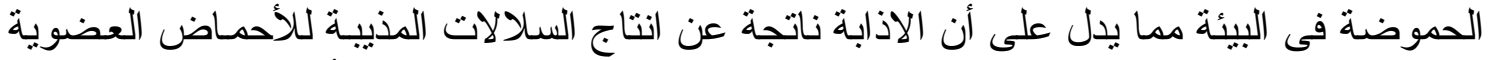

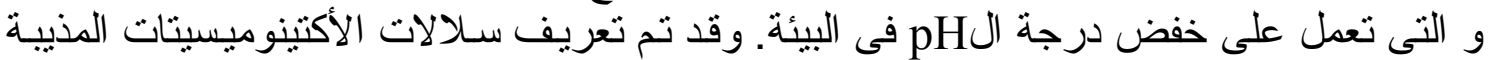

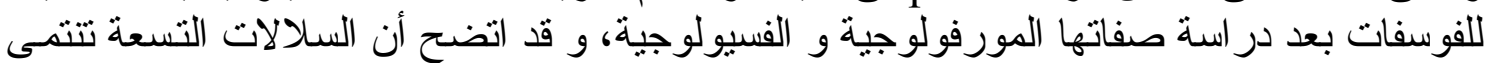

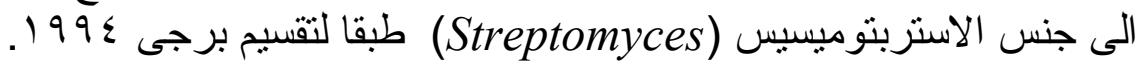

